\title{
STATIC LOADING TEST ON RC BEAM-COLUMN SUB- ASSEMBLAGES WITH WALLS
}

\author{
Seitaro Tajiri ${ }^{1}$ and Akira Moriya ${ }^{2}$
}

(Submitted February 2017; Reviewed July 2017; Accepted September 2017)

\begin{abstract}
It is needed to establish a design capacity curve of beams/columns with RC standing, hanging and wing walls for utilizing such walls as structural members in RC buildings in Japan. This paper presents the results of static loading tests on RC beam-column sub-assemblages with such walls, which were conducted to evaluate their strength, ductility, stiffness and damage. The flexural yield strength of beams with the walls can be well estimated by a flexural analysis assuming the plane section remain plane. The flexural ultimate strength can be accurately estimated at the full plastic moment. The proposed method, which is a modification of a practical design method in a distance from the centre of tensile reinforcements to the extreme compression fibre, can evaluate the secant stiffness at the yield point more precisely than the practical design method.
\end{abstract}

\section{INTRODUCTION}

Most Japanese reinforced concrete (RC) buildings have RC non-structural walls such as wing walls, standing walls and hanging walls as shown in Figure 1. In the practical design of such buildings, the non-structural walls are generally isolated from the adjacent columns and beams by structural gaps between them. This is because it is easy for a structural analysis to model only a beam or a column ignoring the effect of walls. In addition, it is easy to keep high ductility of buildings by preventing shear failure of walls.

If such non-structural $\mathrm{RC}$ walls are utilized as structural walls without separating the walls and the beams/columns, strength and rigidity will be higher, response deformation will decrease, and damage to buildings will decrease by designing the walls with appropriate details. However, modelling such walls with middle column properly for a structural analysis is hard. It is because the research on structural property of such walls are limited although their failure mode, strength and rigidity are different from rectangular $\mathrm{RC}$ walls with end columns.

Therefore, static loading test of interior beam-column subassemblages with RC walls was conducted in order to evaluate their strength, ductility, stiffness and damage. Main parameters of this experimental study were the wall thickness, the amount of column reinforcement, and the length of wing walls.

\section{EXPERIMENTAL PROGRAM}

\begin{abstract}
Specimen Details
Five interior, half-scale-beam-column sub-assemblages were tested. Four of them had wing walls, standing walls and hanging walls, and the other had no walls. Figure 2 shows a benchmark specimen, No.1, which was assumed to represent a lower part of a 6-story RC building whose seismic response coefficient was larger than 0.6. Its columns and beams were designed such that the base shear coefficient of a bare frame without walls was nearly 0.3 which is the minimum requirement of Japanese seismic code. The expected failure mode of the benchmark specimen was flexural failure of both beams with walls at the wing wall interface. The second specimen, No.2, had 1.5 times thicker walls than the No.1. The third specimen, No.3, had a half as many column reinforcement bars as specimen No.1. The fourth specimen, No.4, had a half as long walls as specimen No.1. The fifth specimen had no walls. Figure 3 shows the difference of these specimens from specimen the No.1. Table 1 shows the configuration of all specimens. Table 2 shows mechanical properties of concrete cylinders cured on site, measured when each specimen No.1-5 was tested. Table 3 shows mechanical properties of the reinforcements used. Figure 4 shows the stress-strain of the reinforcements.
\end{abstract}

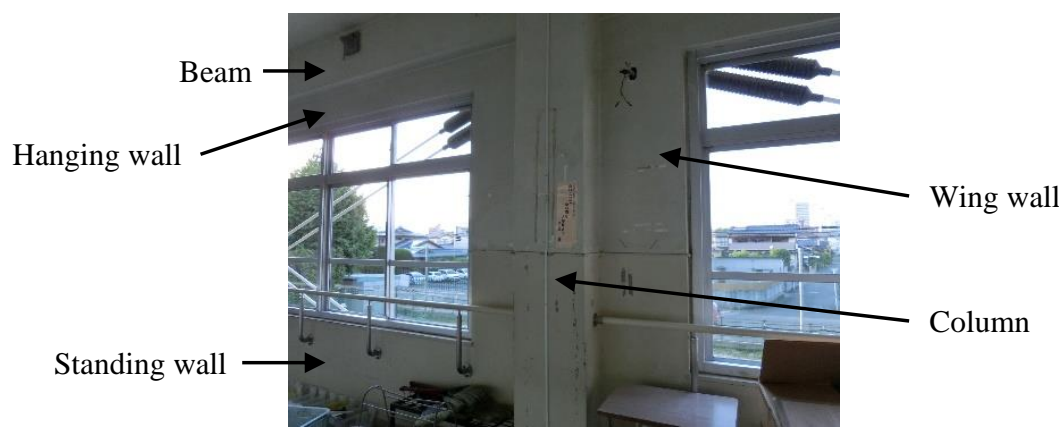

Figure 1: Photo of non-structural walls with a column and beams.

\footnotetext{
${ }^{1}$ Corresponding Author, Associate Professor, University of Tokyo, Tokyo, tajiri@arch.t.u-tokyo.ac.jp

${ }^{2}$ Graduate Student, University of Tokyo, Tokyo
} 


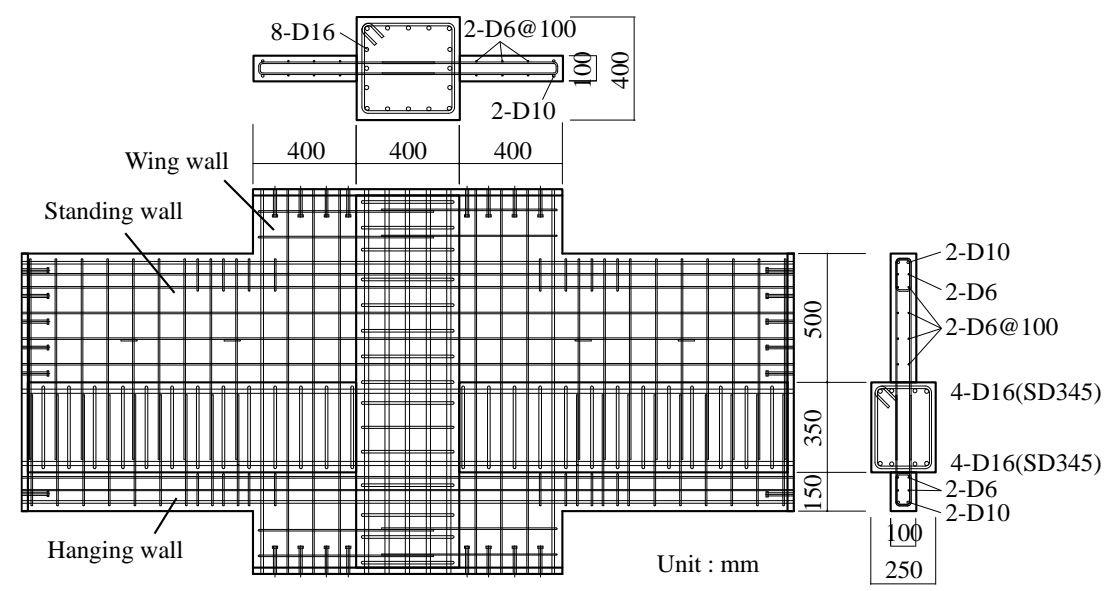

Figure 2: Benchmark specimen (No.1).

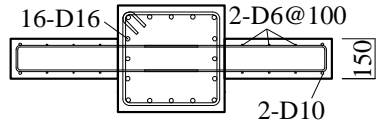

No.2 : Thick walls

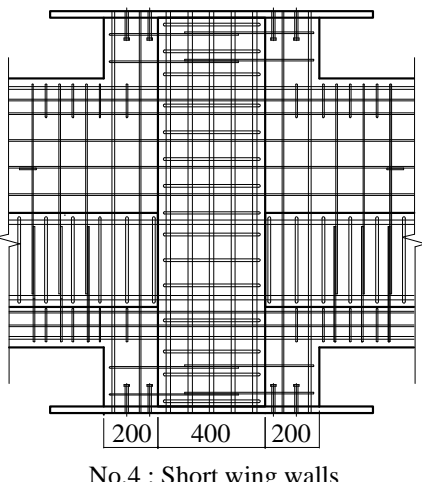

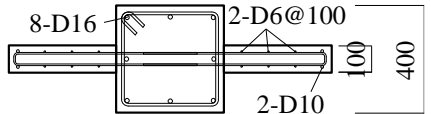

No.3 : Fewer column rebars

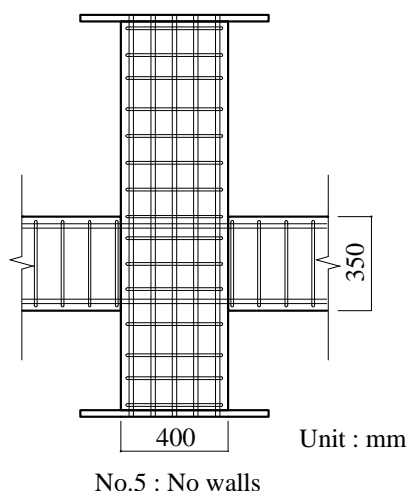

Figure 3: Configuration and bar arrangement of specimens.

Table 1: Configuration of all specimens.

\begin{tabular}{|c|c|c|c|c|c|c|}
\hline & Specimen & No.1 & No.2 & No.3 & No.4 & No.5 \\
\hline \multirow{3}{*}{ Beam } & Width $\mathrm{x}$ depth, mm & \multicolumn{5}{|c|}{$350 \times 250$} \\
\hline & $\begin{array}{l}\text { Reinforcement in tension } \\
\qquad\left(\text { ratio } p_{t}\right)\end{array}$ & \multicolumn{5}{|c|}{$4-\mathrm{D} 16 *\left(\mathrm{SD} 345^{* *}\right)\left(p_{t}=1.01 \%\right)$} \\
\hline & Stirrups (ratio $p_{w}$ ) & \multicolumn{5}{|c|}{ 2-D10*(SD295A**)@100 $\left(p_{w}=0.57 \%\right)$} \\
\hline \multirow{3}{*}{ Column } & Width $\mathrm{x}$ depth, $\mathrm{mm}$ & \multicolumn{5}{|c|}{$400 \times 400$} \\
\hline & Reinforcement (SD345) & \multicolumn{2}{|c|}{ 16-D16* } & 8-D16* & \multicolumn{2}{|c|}{ 16-D16* } \\
\hline & Hoops (ratio $\left.p_{w}\right)$ & \multicolumn{5}{|c|}{$2-\mathrm{D} 10 *(\mathrm{SD} 295 \mathrm{~A} *) @ 100\left(p_{w}=0.36 \%\right)$} \\
\hline Joint & Hoops & \multicolumn{5}{|c|}{$2-\mathrm{D} 10 *\left(\mathrm{SD} 295 \mathrm{~A}^{* *}\right) \times 3$} \\
\hline \multirow{5}{*}{ Wall } & Wing wall length, mm & \multicolumn{3}{|c|}{400} & 200 & \\
\hline & $\begin{array}{l}\text { Length of standing walls } \\
\text { and hanging walls, mm }\end{array}$ & \multicolumn{4}{|c|}{500 and 150} & \\
\hline & Thickness, mm & 100 & 150 & \multicolumn{2}{|c|}{100} & \\
\hline & Reinforcement & \multicolumn{4}{|c|}{ 2-D6*(SD295A**)@100 } & \\
\hline & $\begin{array}{c}\text { Outermost layer of } \\
\text { longitudinal reinforcement }\end{array}$ & \multicolumn{4}{|c|}{$2-\mathrm{D} 10 *(\mathrm{SD} 295 \mathrm{~A} * *)$} & \\
\hline \multicolumn{2}{|c|}{ Column axial force, $\mathrm{kN}$} & \multicolumn{5}{|c|}{720} \\
\hline \multicolumn{2}{|c|}{ Flexural strength ratio of column to beam } & 2.51 & 2.95 & 2.30 & 1.96 & 3.54 \\
\hline
\end{tabular}

* D\# means a deformed bar which is \# $\mathrm{mm}$ in diameter.

* SD\# means that yield strength is \# N/mm². 
Table 2: Measured mechanical properties of concrete.

\begin{tabular}{|c|c|c|c|}
\hline Specimen & $\begin{array}{c}\text { Compressive strength, } \\
\mathrm{MPa}\end{array}$ & Young's modulus, GPa & $\begin{array}{c}\text { Strain at peak } \\
\text { compressive strength, \% }\end{array}$ \\
\hline No.1-4 & 37.1 & 26.8 & 0.23 \\
\hline No.5 & 35.0 & 26.7 & 0.20 \\
\hline
\end{tabular}

Table 3: Mechanical properties of reinforcement.

\begin{tabular}{|c|c|c|c|}
\hline Type & Yield strength, MPa & Young's modulus, GPa & Ultimate tensile strength, MPa \\
\hline D16(SD345) & 388.4 & 186.9 & 563.9 \\
\hline D10(SD295A) & 358.8 & 188.6 & 518.6 \\
\hline D6(SD295A) & $439.4 *$ & 191.7 & 543.8 \\
\hline
\end{tabular}

$* 0.2 \%$ proof stress
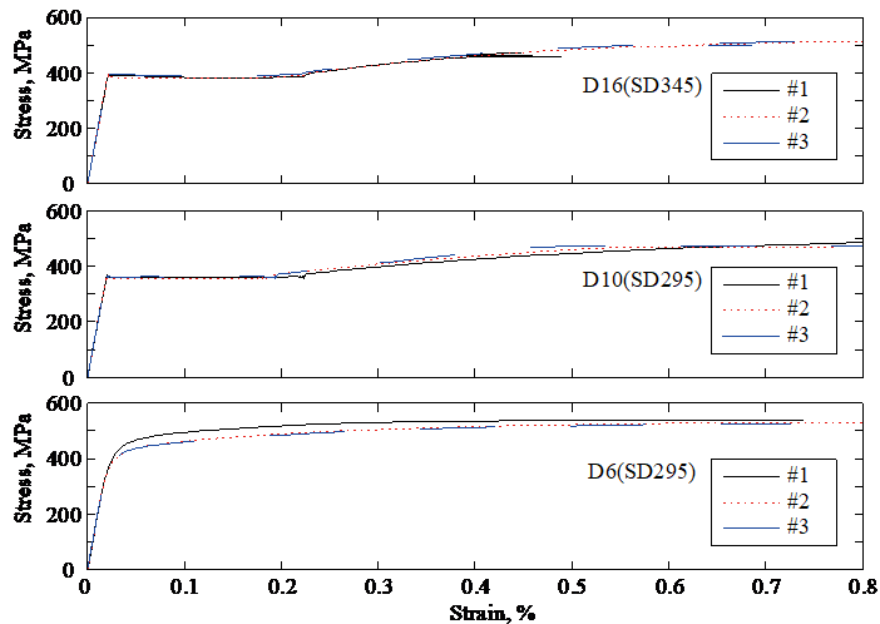

Figure 4: Stress-strain of reinforcements.

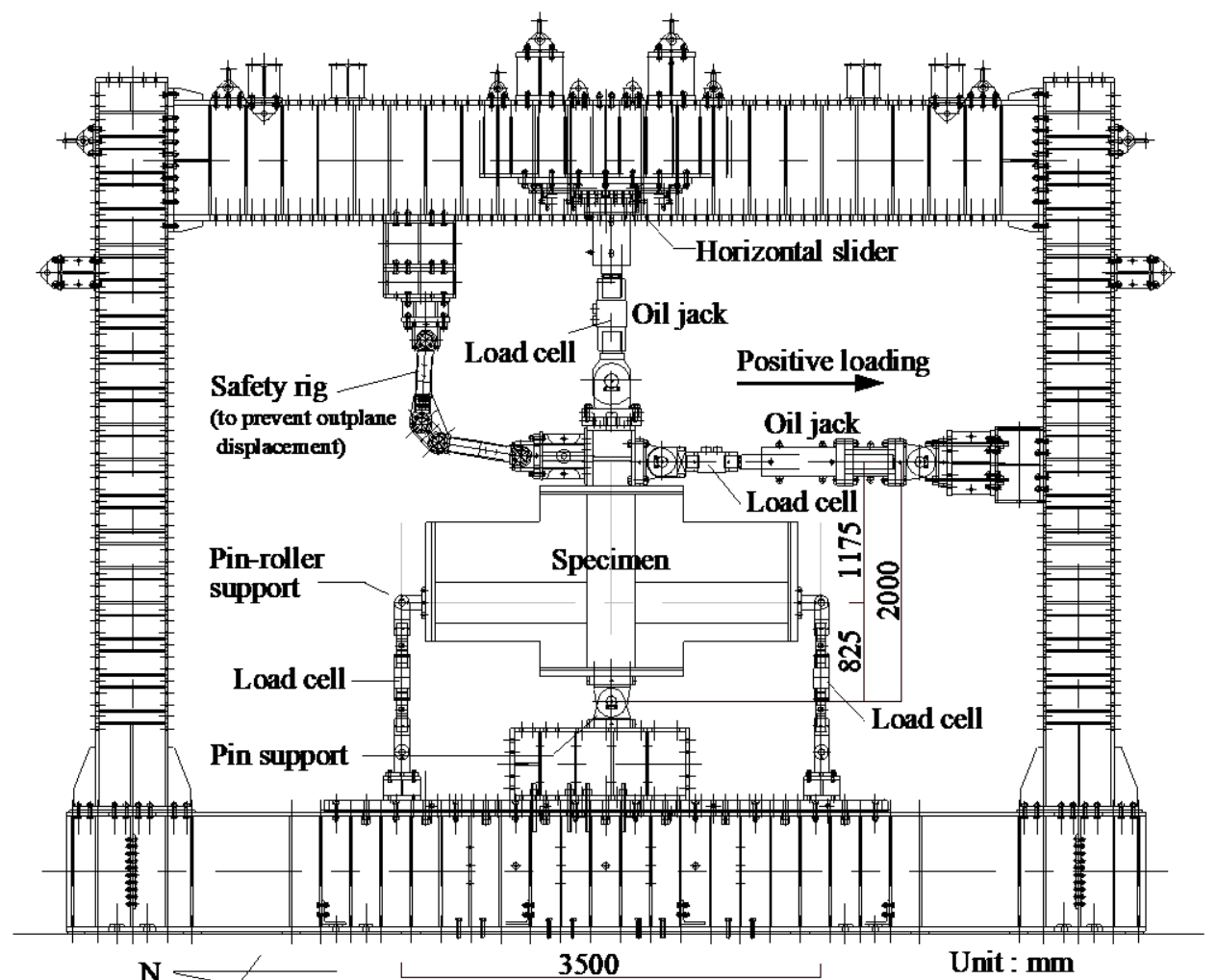

Figure 5: Loading setup. 


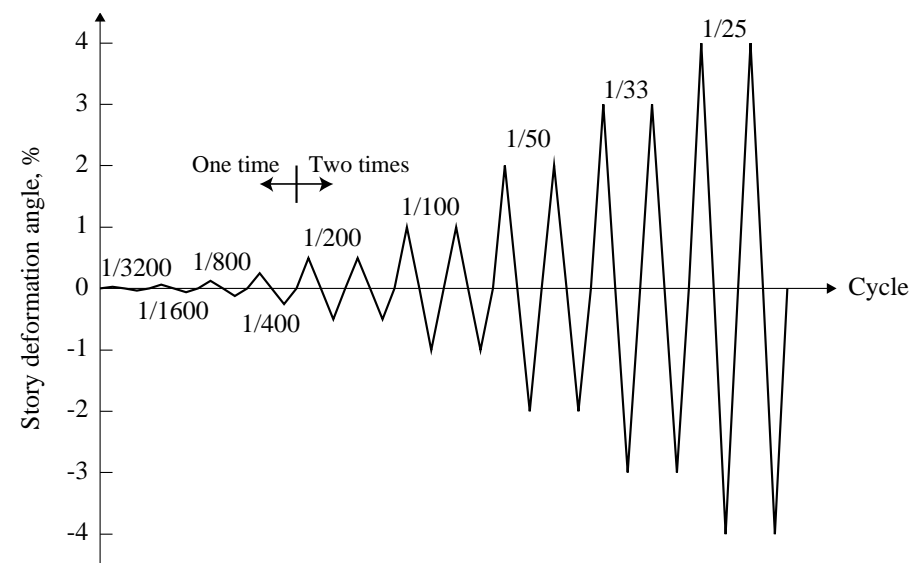

Figure 6: Loading protocol.

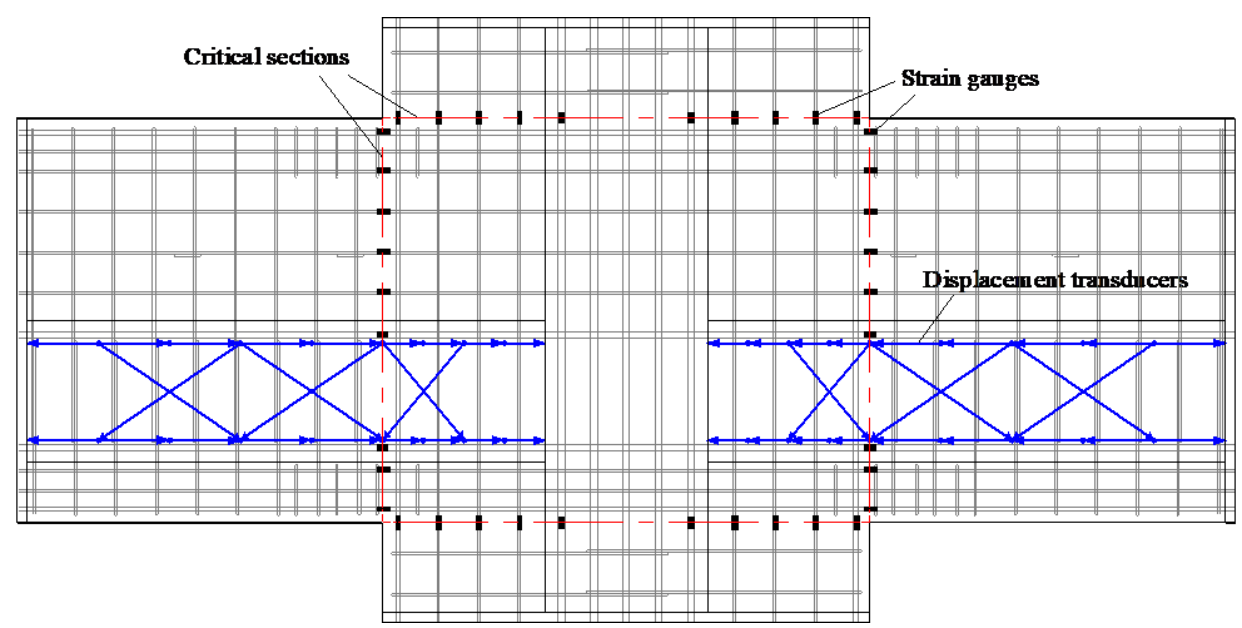

Figure 7: Location of measurement instruments.

\section{Loading Setup and Measurement}

Figure 5 shows the experimental setup which is a loading system in Building Research Institute (BRI) in Tsukuba, Japan. The specimen was pin supported at the bottom, and pin-roller supported at the outer ends of both beams. Constant vertical load $720 \mathrm{kN}$, which corresponds to 0.12 in axial force ratio for columns of the No.1-4 and 0.13 for the column of the No.5, was applied to the top of the specimen. The vertical actuator shown in Figure 5 was controlled to keep constant force automatically during the test. In addition, horizontal cyclic deformation shown in Figure 6 was applied through the horizontal actuators. The loading test finished after the $4 \%$ drift loading.

The vertical and horizontal forces applied to the top of the specimen and reaction forces at both pin-roller support were measured with four load cells. Overall deformations of columns and beams and curvatures of beams were measured with transducers. In addition, strains of reinforcements in the beams, columns and walls at the critical sections as shown in Figure 7 were measured.

\section{EXPERIMENTAL RESULT}

\section{Damage Pattern}

All of the specimens with walls (No.1-4) showed a similar damage pattern. At first, flexural cracks occurred from the corner of walls at $1 / 3200$ in story drift. Flexural cracks expanded and extended to beams at 1/1600 drift. At 1/800 drift, flexural cracks of walls expanded inside wing walls. Flexural cracks of beam at the surface of the column and shear cracks of standing walls were observed at 1/400 drift. When story drift reached $1 / 200$, concrete was about to crush at the corner of walls for specimens No.1-3 and flexural cracks occurred in columns. After $1 \%$ loading, severe spalling of concrete was observed at the corner of walls for specimens No.1 and No.3, compared to minor concrete spalling occurring in specimens No. 2 and No.4. Each specimen showed flexural compression failure of beams with walls during $1 \%$ loading. Wall longitudinal reinforcement buckled during 2\% loading for specimens No.2 and No.4 and 1\% loading for specimens No.1 and No.3. All the specimens with walls were severely damaged at the end of beams after the final loading. The observed failure mode was flexural failure of beams with walls as expected. As for the specimen No.1, flexural cracks occurred at beam ends at 1/3200 drift. After that more flexural cracks occurred at beam ends as the drift was larger, and both beams yielded in flexure during $1 \%$ loading. Figure 8 shows photos of all the specimen at the first $2 \%$ loading in positive. Figure 9 shows photos of the specimen No.1 at the first $0.5 \%$, $1 \%, 4 \%$ drift. 
Flexural failure at the surface of a wing wall

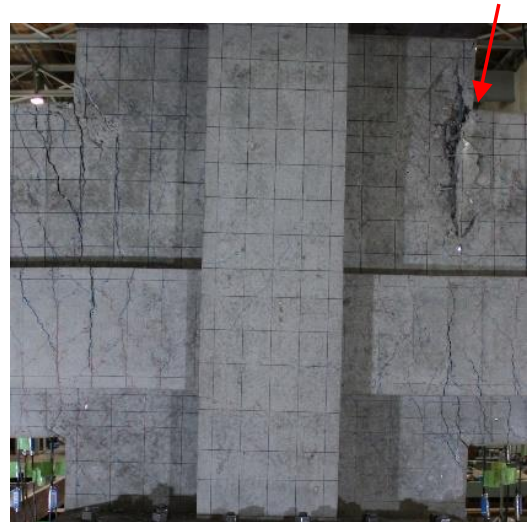

No.1

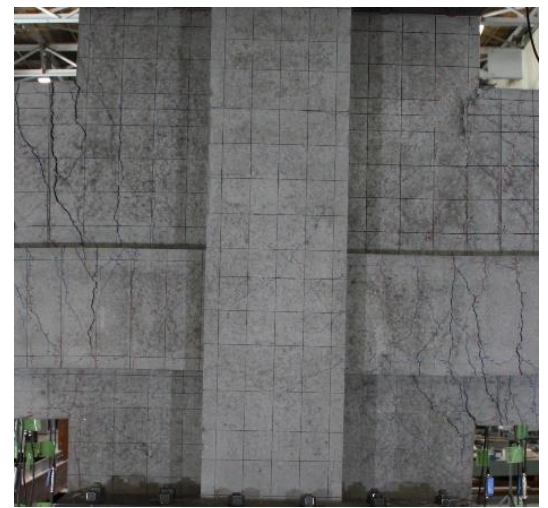

No.2

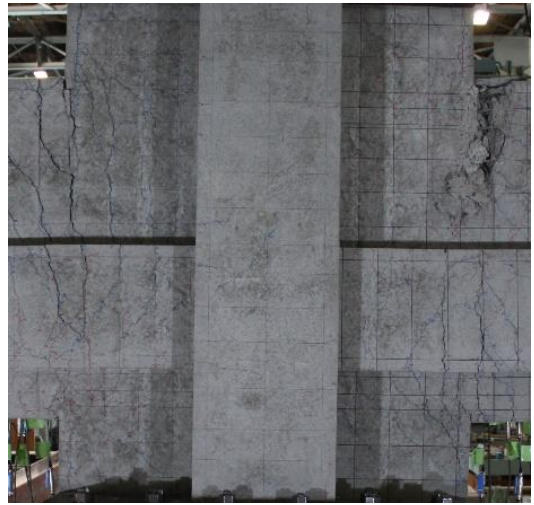

No.3

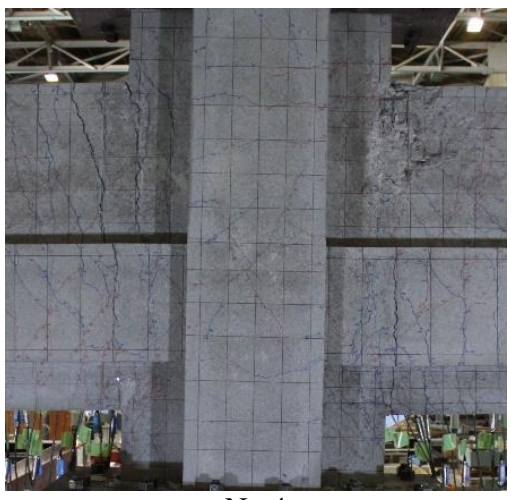

No.4

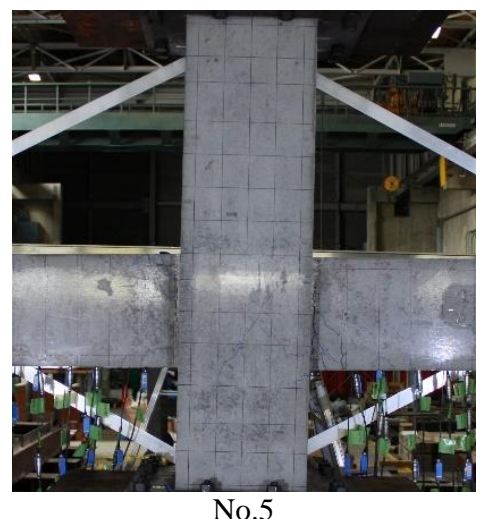

No.5

Figure 8: Damage to specimens at $2 \%$ drift.
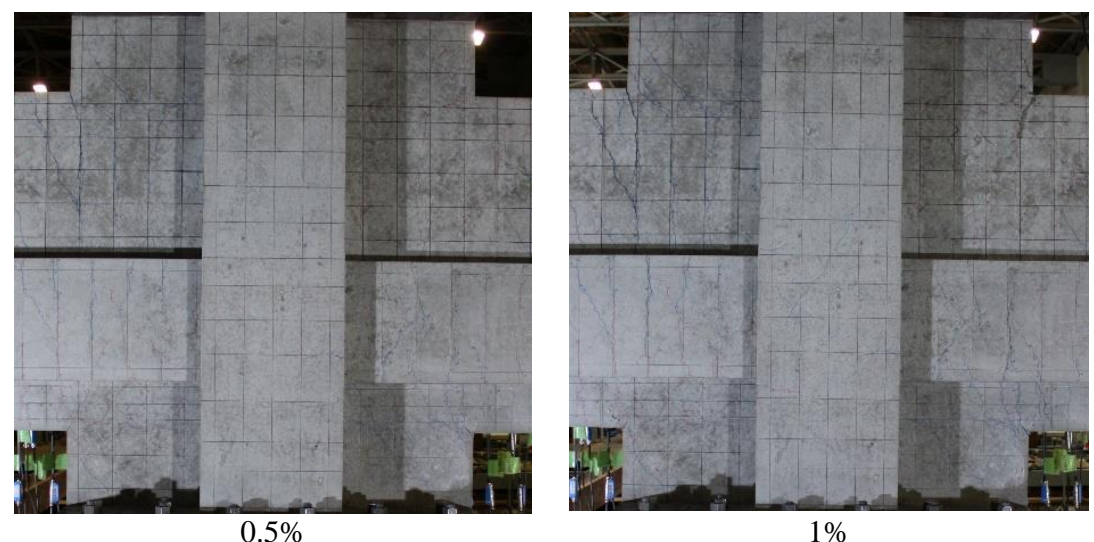

$1 \%$

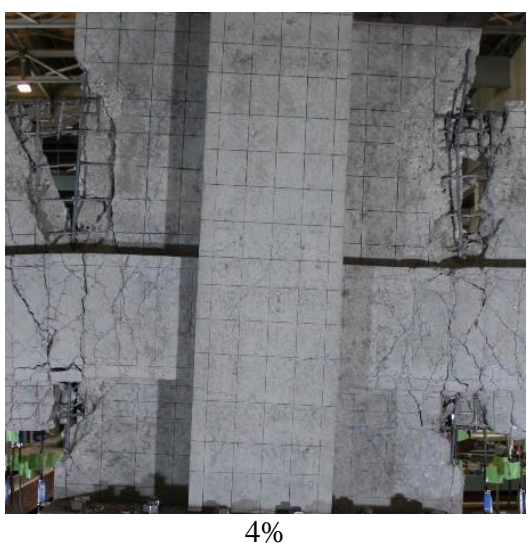

Figure 9: Damage to specimens No.1 at 0.5\%, $1 \%$ and $4 \%$ drift.

\section{Story Shear and Drift}

Figure 10 shows story shear v. story drift angle response for all specimens, and Figure 11 shows their backbone curves. Figure 10 also shows the points when longitudinal reinforcement of beams and walls yielded. It is difficult to decide the yield point of a beam with walls because it has many layers of longitudinal reinforcement. Such a member does not show an obvious yielding point because the reinforcement gradually yields as the applied moment increases. Here, the yielding point of a beam with walls is defined as when its longitudinal reinforcements in the beam, not in the walls, yield at first. At first, longitudinal reinforcement of standing walls yielded before those of hanging walls did. After the reinforcement of standing and hanging walls yielding, beam longitudinal reinforcement yielded and story shear reached a maximum where concrete crushing occurred at the corner of standing walls. After that, rapid deterioration occurred, although hysteresis loops were fat.

The thick wall specimen, No.2, showed $15 \%$ larger secant stiffness when a beam longitudinal reinforcement yielded than No.1 in the positive direction and $23 \%$ larger in the negative direction. Story shear deterioration after the maximum strength of specimen No.1 was slower than that of specimen No.2; up to $2 \%$ drift in the positive direction and $4 \%$ drift in the negative direction, although story shear at drift greater than $2 \%$ was almost the same as that of specimen No.1 in the positive direction. The few column reinforcement specimen No.3 showed almost the same load deformation as specimen No.1. The secant stiffness at beam reinforcement yielding of the short wing wall specimen, No.4, was $31 \%$ lower in the positive direction and $24 \%$ lower in the negative direction than that of specimen No.1. Although story shear of specimen No.4 up to $1 \%$ drift was lower than that of specimen No.1, it 
showed almost the same shear as specimen No.1 at 2-3\% drift, and higher story shear at $4 \%$ drift. The hysteresis loop of the no walls specimen, No.5, was fat, but became a little S-shaped at large drifts. The shear force of the No.5 at $4 \%$ drift was $43 \%$ lower than that of the No.1.

\section{Maximum Strength of Beam}

All the specimens with walls failed in beam with walls flexure at the surface of wing walls as shown in Figure 10. The observed maximum shear forces of the two beams, which corresponds to maximum reaction forces at pin-roller
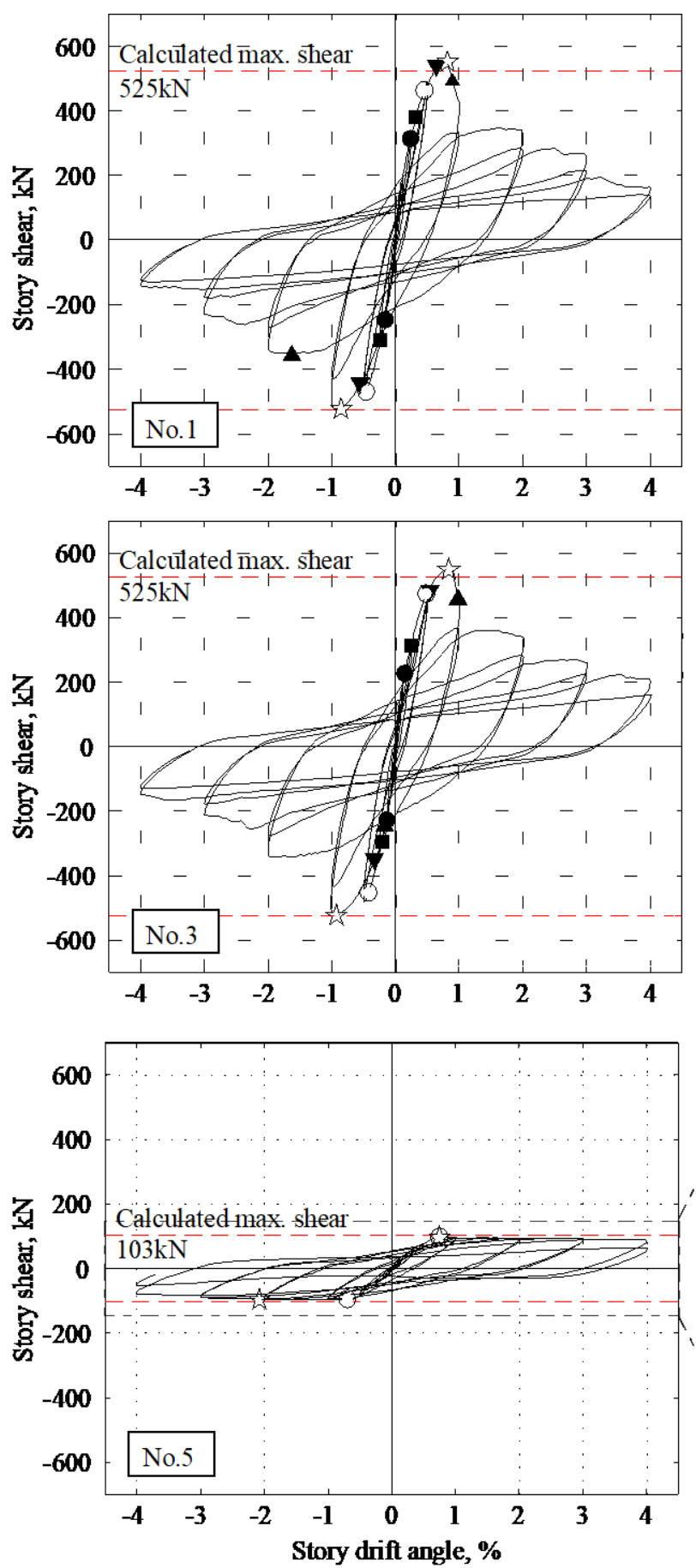

supports, are shown in Table 4. In addition, the table shows shear forces corresponding when a moment of a beam with walls reached its calculated flexural strengths at the surface of wing walls. Here, two methodologies shown in a technical description for a practical design ${ }^{1}$ are used to calculate the flexural strengths. One is to calculate flexural strength of an assumed rectangular beam, which has the same area and height as those of the original section of the beam with walls, where tensile reinforcement of a beam and a wall concentrate on the gravity centre of all the tensile reinforcements. The other is to calculate full plastic moment of the original section. The difference of the methodologies is shown in Figure 12.
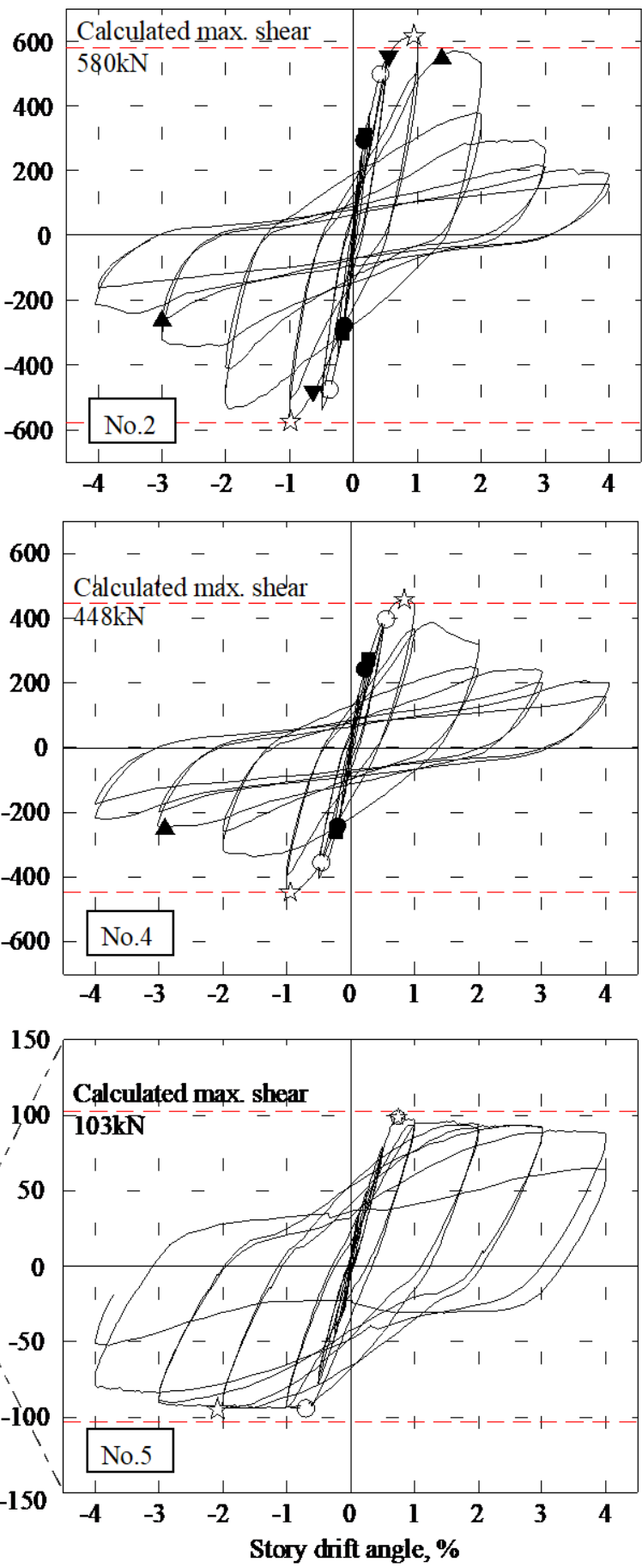

Yield in a longitudinal rebar of

$\bigcirc$ beam - standing wall $\square$ hanging wall $\Delta$ upper wing wall $\nabla$ lower wing wall is Maximum shear

Figure 10: Story shear and drift. 
The ratios of the calculated strength to the observed strength are also shown in Table 4. As a result, a flexural strength of the beam with walls calculated by the first methodology underestimates the observed one, especially in the direction a hanging wall is in tension. All the beam longitudinal reinforcements are in tension when hanging wall is in tension because hanging walls are much shorter than standing walls. This is different from the assumption of the first methodology to calculate maximum strength. Therefore, when standing wall is in tension is more conservative than that when hanging wall is in tension. Whereas, the flexural strength calculated by the second methodology matches well with the observed strengths.

\section{Yield Strength of Beam}

Table 5 shows the yield flexural strengths of beams with walls of the specimens No.1-No.4. In addition, shear forces acting at the flexural yield strength is calculated by fibre analyses for the beams with walls assuming that plane sections remain plane after deformation. The ratios of the calculated flexural yield strength to the observed strength are nearly 1.0, indicating the strain compatibility and plane section remain plane approach can accurately evaluate the flexural yield strength of a beam with walls calculated.

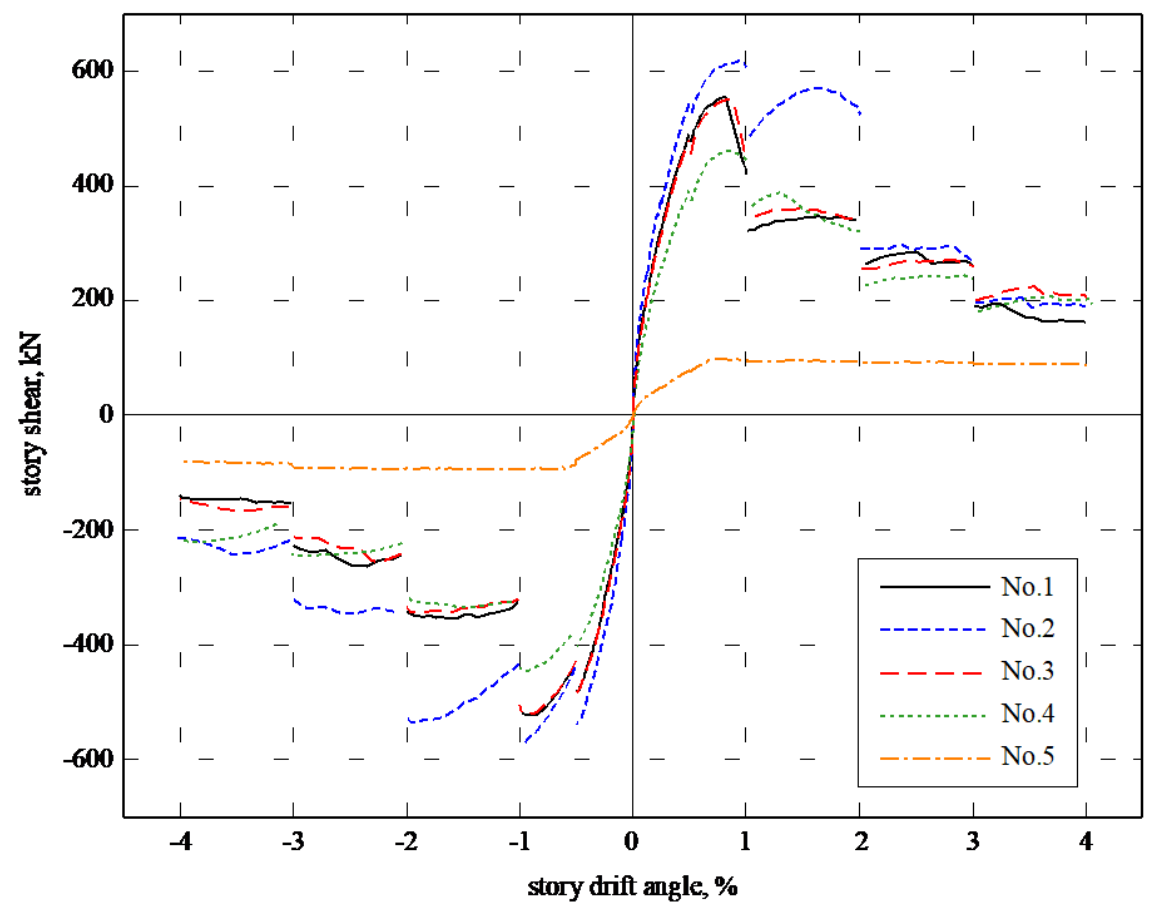

Figure 11: Backbone curves.

Table 4: Shear force at maximum flexural strength of beams.

\begin{tabular}{|c|c|c|c|c|c|c|c|c|c|}
\hline \multirow{2}{*}{\multicolumn{2}{|c|}{ Specimen }} & \multicolumn{2}{|c|}{ No.1 } & \multicolumn{2}{|c|}{ No. 2} & \multicolumn{2}{|c|}{ No.3 } & \multicolumn{2}{|c|}{ No.4 } \\
\hline & & \multirow{2}{*}{$\frac{\text { North }}{258}$} & \multirow{2}{*}{$\frac{\text { South }}{244}$} & \multirow{2}{*}{$\frac{\text { North }}{280}$} & \multirow{2}{*}{$\frac{\text { South }}{254}$} & \multirow{2}{*}{$\frac{\text { North }}{252}$} & \multirow{2}{*}{$\frac{\text { South }}{245}$} & \multirow{2}{*}{$\frac{\text { North }}{212}$} & \multirow{2}{*}{$\frac{\text { South }}{207}$} \\
\hline \multirow{5}{*}{$\begin{array}{l}\text { Standing wall } \\
\text { is in tension }\end{array}$} & Observed & & & & & & & & \\
\hline & Calculated (1) & \multicolumn{2}{|c|}{225} & \multicolumn{2}{|c|}{236} & \multicolumn{2}{|c|}{225} & \multicolumn{2}{|c|}{191} \\
\hline & Calc. (1) / Obs. & 0.87 & 0.92 & 0.84 & 0.93 & 0.89 & 0.92 & 0.90 & 0.93 \\
\hline & Calculated (2) & \multicolumn{2}{|c|}{229} & \multicolumn{2}{|c|}{249} & \multicolumn{2}{|c|}{229} & \multicolumn{2}{|c|}{195} \\
\hline & Calc. (2) / Obs. & 0.89 & 0.94 & 0.89 & 0.98 & 0.91 & 0.93 & 0.92 & 0.94 \\
\hline \multirow{5}{*}{$\begin{array}{l}\text { Hanging wall } \\
\text { is in tension }\end{array}$} & Observed & 362 & 388 & 409 & 436 & 360 & 386 & 309 & 322 \\
\hline & Calculated (1) & \multicolumn{2}{|c|}{282} & \multicolumn{2}{|c|}{290} & \multicolumn{2}{|c|}{282} & \multicolumn{2}{|c|}{240} \\
\hline & Calc. (1) / Obs. & 0.78 & 0.73 & 0.71 & 0.66 & 0.78 & 0.73 & 0.77 & 0.74 \\
\hline & Calculated (2) & \multicolumn{2}{|c|}{383} & \multicolumn{2}{|c|}{412} & \multicolumn{2}{|c|}{383} & \multicolumn{2}{|c|}{326} \\
\hline & Calc. (2) / Obs. & 1.06 & 0.99 & 1.01 & 0.95 & 1.06 & 0.99 & 1.06 & 1.01 \\
\hline
\end{tabular}




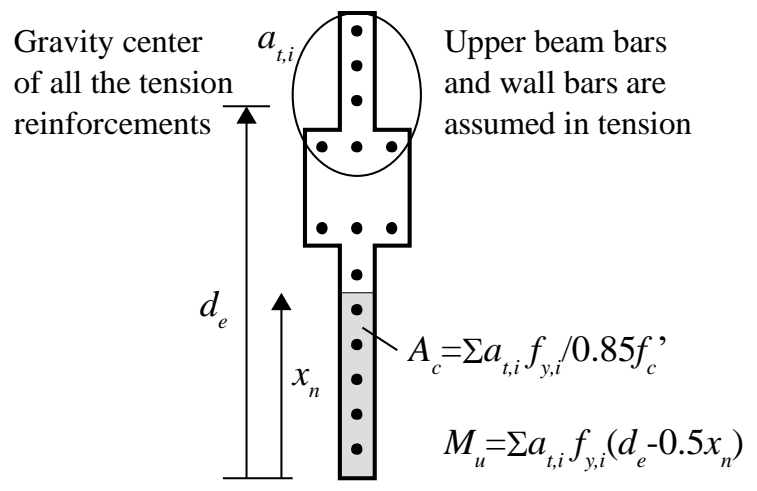

First methodology

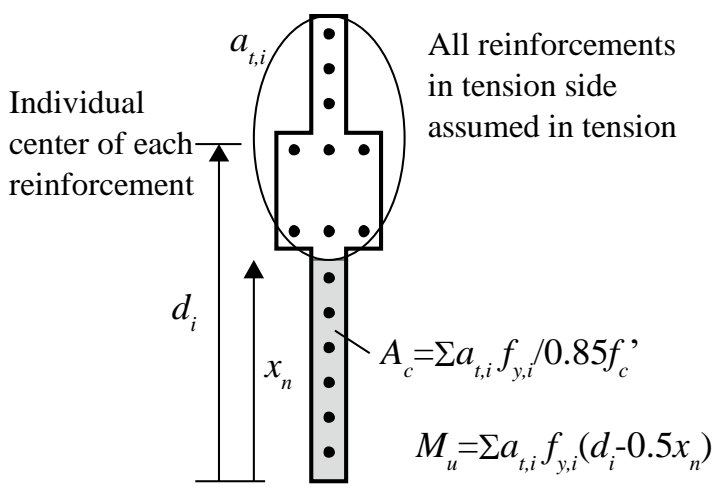

Second methodology

Figure 12: Difference of methodologies to calculate maximum strength of a beam with walls.

Table 5: Shear force at yield flexural strength of beams.

\begin{tabular}{|c|c|c|c|c|c|c|c|c|c|}
\hline \multirow{2}{*}{\multicolumn{2}{|c|}{ Specimen }} & \multicolumn{2}{|c|}{ No.1 } & \multicolumn{2}{|c|}{ No.2 } & \multicolumn{2}{|c|}{ No.3 } & \multicolumn{2}{|c|}{ No.4 } \\
\hline & & North & South & North & South & North & South & North & South \\
\hline \multirow{3}{*}{$\begin{array}{l}\text { Standing wall } \\
\text { is in tension }\end{array}$} & Observed & 224 & $\mathrm{NA}^{*}$ & 242 & 250 & 237 & NA* & 209 & 181 \\
\hline & Calculated & \multicolumn{2}{|c|}{222} & \multicolumn{2}{|c|}{230} & \multicolumn{2}{|c|}{222} & \multicolumn{2}{|c|}{189} \\
\hline & Calc. / Obs. & 0.91 & NA & 0.95 & 0.92 & 0.94 & NA & 0.90 & 1.05 \\
\hline \multirow{3}{*}{$\begin{array}{l}\text { Hanging wall is } \\
\text { in tension }\end{array}$} & Observed & 316 & 326 & 341 & 356 & 323 & 314 & 273 & 290 \\
\hline & Calculated & \multicolumn{2}{|c|}{318} & \multicolumn{2}{|c|}{332} & \multicolumn{2}{|c|}{318} & \multicolumn{2}{|c|}{271} \\
\hline & Calc. / Obs. & 1.01 & 0.98 & 0.97 & 0.93 & 0.99 & 1.01 & 0.99 & 0.94 \\
\hline
\end{tabular}

* South beams of No.1 and No.3 first yielded in the opposite loading direction.
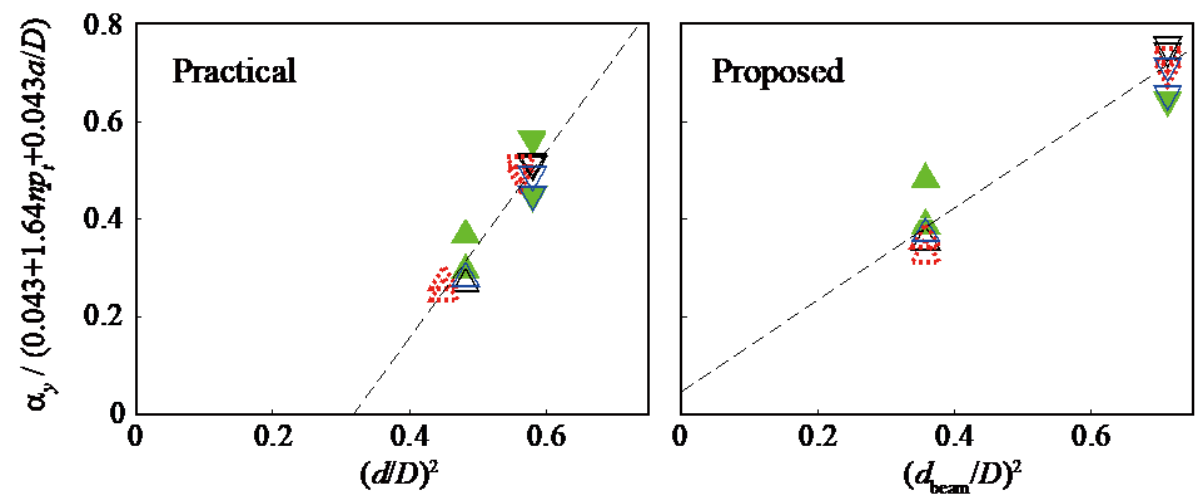

Standing wall is in tension $\triangle$ No.1 No.2 $\triangle$ No.3 $\triangle$ No.4 Hanging wall is in tension $\nabla$ No.1 No.2 $\nabla$ No.3 $\nabla$ No.4

Figure 13: Secant stiffness of beams with walls at yielding point.
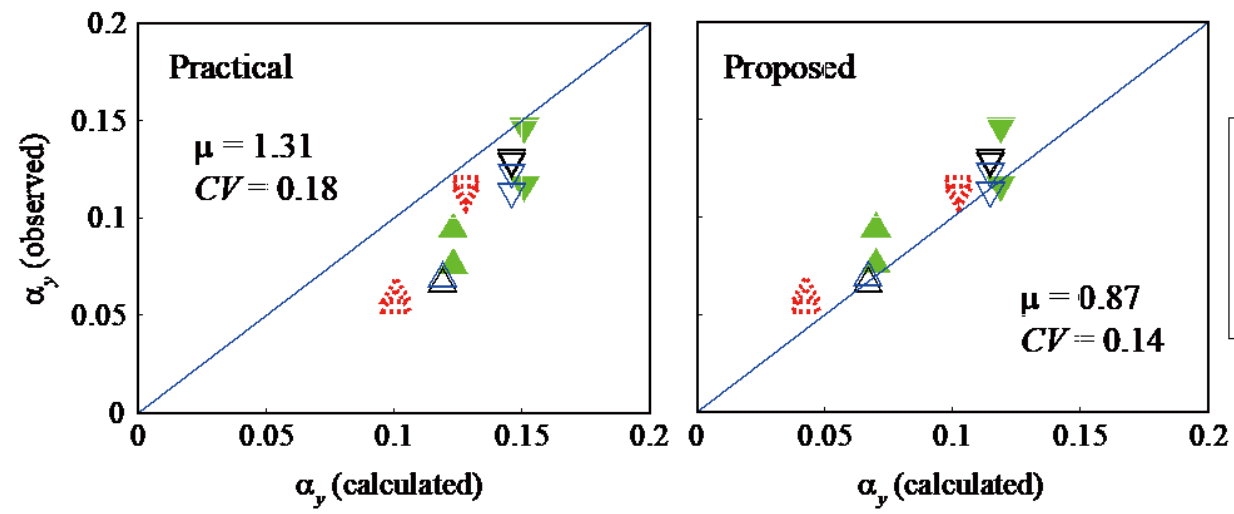

Standing wall is in tension $\triangle$ No.1 No.2 $\triangle$ No.3 $\triangle$ No.4

Hanging wall is in tension

$\nabla$ No.1 ${ }_{3}$ No.2 $\nabla$ No.3 $\nabla$ No.4

Figure 14: Secant stiffness of beams with walls at yielding point. 

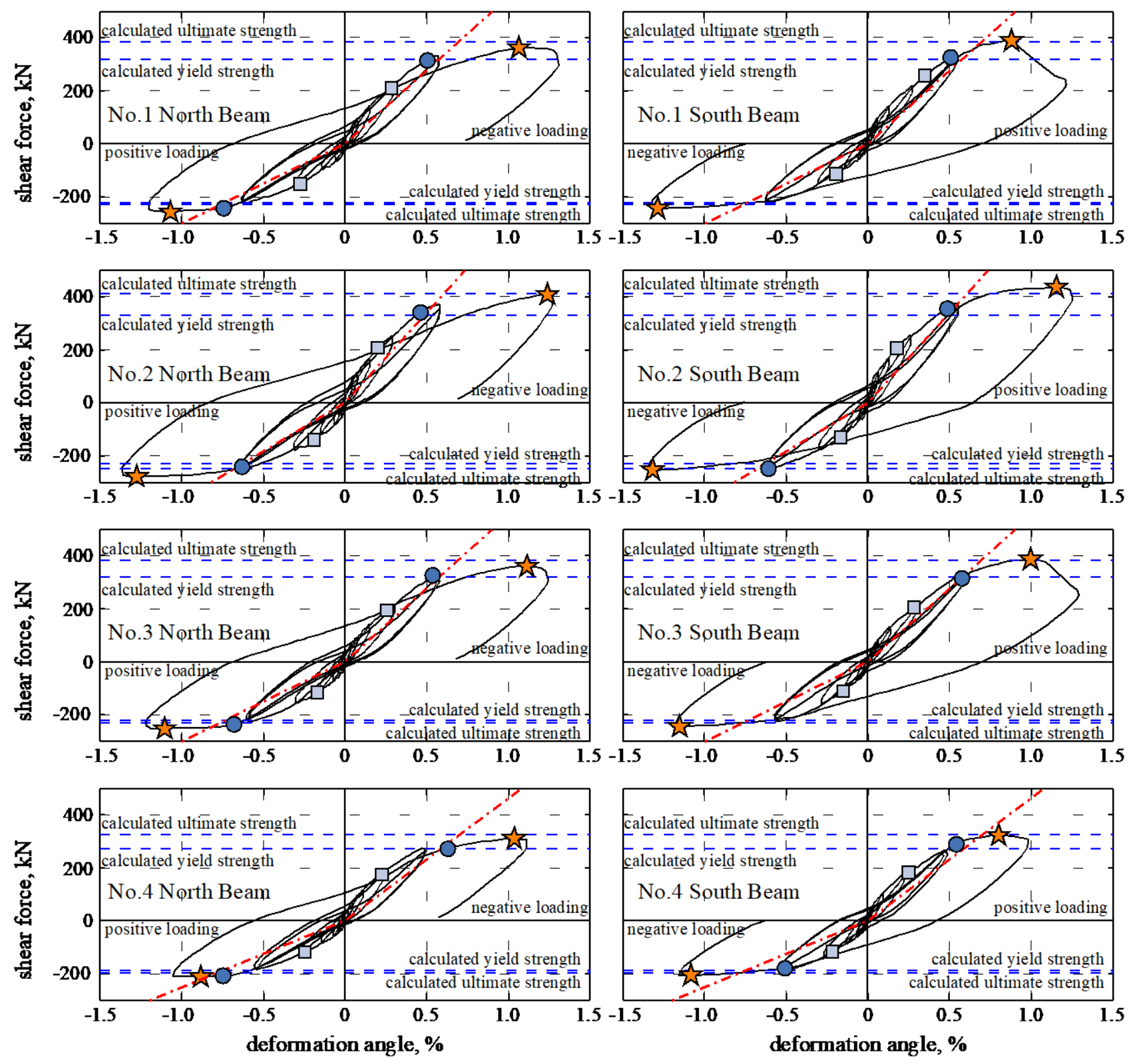

O Beam rebar yield $\square$ Wall rebar yield Maximum shear

$\cdot \cdot \cdot \cdot \cdot \cdot-$ Calculated secant stiffness at yield point

Figure 15: Force-deformation of beams with walls showing the secant stiffness.

\section{Secant Stiffness at Yielding Point}

The ratio of the secant stiffness at yielding point to the calculated initial stiffness, $\alpha_{y}$, is usually calculated for a rectangular beam by formula $(1)^{2}$.

$\alpha_{y}=\left(0.043+1.64 n p_{t}+0.043 \frac{a}{D}\right) \cdot\left(\frac{d}{D}\right)^{2}$

where, $n$ is the ratio of Young's modulus of steel to that of concrete, $p_{t}$ is a tensile reinforcement ratio, $a$ is a shear span, $D$ is a beam height, and $d$ is a distance from the centre of resultant of tensile force to the extreme compression fibre.

The initial stiffness used for calculating $\alpha_{y}$ usually only accounts for flexural stiffness of concrete because the effects of a shear stiffness and reinforcement almost cancel each other, however, all the effects are taken into account for calculating an initial stiffness of the beam with walls because they are not necessarily cancellable for such a wall-like member.
According to formula (1), $\alpha_{y}$ is proportional to $(d / D)^{2}$, that means factor $d / D$ affects the value of $\alpha_{y}$ more than any other factors such as $n, p_{t}$, and $a / D$. This is why a relationship between $d / D$ and $\alpha_{y}$ that Figure 13 shows is checked. The horizontal axis shows $d / D$, and the vertical axis shows $\alpha_{y}$ divided by $\left(0.043+1.64 n p_{t}+0.043 a / D\right)$. In the practical design, $d$ is taken as the distance from the extreme compressive fibre to the centre of the resultant of tension reinforcements when first yielding of longitudinal reinforcement occurs in the walls. As shown in the left-side figure, observed $\alpha_{y}$ values are not proportional to $(d / D)^{2}$ under such condition. Then, the distance, $d_{\text {beam, }}$ corresponding to first yield of longitudinal reinforcement in the beam is applied. Consequently, $\alpha_{y}$ values are almost proportional to $\left(d_{\text {beam }} / D\right)^{2}$ as shown in the right-side figure, which indicates using $d_{\text {beam }}$ is much more appropriate. Figure 14, which compares observed $\alpha_{y}$ with calculated ay by practical and proposed method, shows that the proposed can estimate $\alpha_{y}$ better than the practical one. 


\section{Observed and Calculated Force-Deformation Curves}

Figure 15 shows shear force and overall deformation of beams with walls. It also shows the proposed secant stiffness as well as the flexural yield strength calculated by the fibre analysis and the maximum flexural strength calculated by the fibre analysis assuming fully plastic state. Comparing lines of calculated ultimate strength with star markers, lines of calculated yield strength with circle markers, and lines of calculated secant stiffness at yield points with circle markers, calculated ultimate strength, yield strength, and secant stiffness are good enough to evaluate the observed value. The precision was shown in each section before.

\section{CONCLUSIONS}

Five interior-column sub-assemblages, four of which are with RC non-structural walls, was statically cyclic loaded. The following conclusions can be made.

1. All the specimens with walls failed in beam with walls flexure at the surface of wing walls as expected.

2. Decreasing column reinforcement could be permitted if the strength of column with wing walls is sufficient to achieve a beam governed failure mode.

3. The observed maximum flexural strength of the beams with walls meet the calculated values when assuming full plastic state, although the other methodology overestimated.

4. Flexural yield strength of the beams with walls, where a beam tensile reinforcement first yields, can be well estimated by the section analysis which assumes that plane section remain plain after deformation.

5. Secant stiffness at the yielding point of the beams with walls can be accurately estimated with modification of the practical design.

6. The strength of the sub-assemblages with walls deteriorates rapidly after reaching maximum strength, however, achieves a much larger strength than the specimen without walls even in the large deformation.

7. Thick and reinforced walls are effective to acquire high strength and ductility for a bare frame.

\section{ACKNOWLEDGEMENT}

This work was supported by JSPS KAKENHI Grant Number JP25709050.

\section{REFERENCES}

1 Information Center for Building Administration and Japan Building Disaster Prevention Association (2015). "Guideline for Structural Standard of Buildings". Official Gazette Co-operation of Japan, Tokyo, 785pp (in Japanese).

2 Sugano S (1973). "Research on Load Deformation Relationship of RC members: Experimental Study for Strength and Stiffness of Flexural Beam, Column and Shear Wall without Opening”. Concrete Journal, 11(2): 19 (in Japanese). 